\title{
Controle de amarelinho (Tecoma stans) em pastagem com aplicações localizadas de herbicidas ${ }^{1}$
}

\section{Yellow bells (Tecoma stans) control in pasture with localized applications of herbicides}

\section{Rafael Romero Mendes ${ }^{2}$; Denis Fernando Biffe ${ }^{3}$; Jamil Constantin ${ }^{3}$; Rubem Silvério de Oliveira $\mathrm{Jr}^{3}$; Ênio Lemes Rosa ${ }^{4}$; André Lucas Faccin Cuba ${ }^{5}$; Rodrigo Barilari Baladeli ${ }^{5}$}

Resumo - A presença de amarelinho (Tecoma stans) em áreas de pastagem pode comprometer a formação e o desenvolvimento das plantas forrageiras, o que prejudica a produção animal, além de dificultar operações mecanizadas com a utilização de implementos de arrasto. O objetivo deste trabalho foi avaliar o controle de amarelinho com herbicidas associados a métodos de aplicação localizada, bem como a fitointoxicação da pastagem composta por capim-tanzânia (Panicum maximum cv. Tanzânia). Os tratamentos foram triclopyr (4\%) e triclopyr (3\%) aplicados na base das plantas $(\mathrm{AB})$; picloram $(2 \%)$ aplicado no toco das plantas após o corte (AT); triclopyr + picloram $(1 \%+1 \%)$ e triclopyr + picloram $(2 \%+2 \%) \mathrm{AB}$, mais uma testemunha sem aplicação e uma testemunha roçada. Todos os tratamentos com herbicidas resultaram em níveis de controle acima de $95 \%$ aos 270 dias após a aplicação, sendo mais eficientes do que o tratamento apenas com a roçada da parte aérea, em função da capacidade de rebrote das plantas. Os herbicidas causaram injúrias à pastagem, mas apenas na área localizada imediatamente ao redor das plantas que receberam aplicação.

Palavras-chaves: aplicação na base; aplicação no toco; picloram; triclopyr

\begin{abstract}
The presence of yellow bells (Tecoma stans) in pastures can compromise the implantation and the development of forage, damaging animal production and hindering mechanized operations with trailing implements. The objective of this paper was to evaluate the yellow bells control after localized herbicides applications and the fitointoxication of pasture composed of Urochloa maxima (syn Panicum maximum). The treatments were triclopyr (4\%) and triclopyr (3\%) applied to the stump base (SB); picloram (2\%) applied on stump after plants (SA); triclopyr + picloram $(1 \%+1 \%)$ and triclopyr + picloram $(2 \%+2 \%) \mathrm{SB}$; plus a check without herbicide application and a check where plants were mowed. All herbicides treatments resulted over $95 \%$ control 270 days after application and were more efficient than stump cut treatment, which showed capacity of regrowth. The herbicides promoted injures on pasture, however the symptoms were observed only in the area located around the $T$. stans plants.
\end{abstract}

Keywords: base application; stump application; picloram; triclopyr

\footnotetext{
${ }^{1}$ Recebido para publicação em 29/08/2016 e aceito em 08/10/2016.

${ }^{2}$ Mestrando em Agronomia na Universidade Estadual de Maringá (NAPD/UEM). Maringá, PR, Brasil. E-mail: <rafaromero.mendes@gmail.com>.

${ }^{3}$ Professor Associado do Departamento de Agronomia da Universidade Estadual de Maringá (NAPD/UEM). Maringá, PR, Brasil. E-mail: <denisbiffe@gmail.com; constantin@teracom.com.br; rubem.oliveirajr@gmail.com>.

${ }^{4}$ Pesquisador vinculado à Nortox S/A. Aranpongas, PR, Brasil. E-mail: <enio@ nortox.com.br>.

${ }^{5}$ Aluno de graduação da Faculdade de Agronomia da Universidade Estadual de Maringá (NAPD/UEM). Maringá, PR, Brasil. E-mail: <delucas8@ @otmail.com; rodrigobarilari@outlook.com>.
} 


\section{Introdução}

A produção de carne bovina no Brasil tende a continuar aumentando nas próximas décadas, em virtude da melhora na genética e na nutrição animal e aumento pela demanda nacional e internacional do produto (OECD/FAO, 2015). O panorama poderia ser melhor, visto que a maioria da produção de bovinos no Brasil é oriunda da pecuária extensiva e a ampla degradação de pastagens se caracteriza como um dos maiores problemas da pecuária brasileira. A baixa qualidade e produtividade das pastagens no País, frequentemente estão associadas à elevada ocorrência de plantas daninhas (Souza Filho, 2006).

As plantas daninhas podem ser responsáveis por ferimentos nos animais, causando a desvalorização do couro e, em alguns casos, podem apresentar efeito tóxico quando ingeridas. São espécies que podem comprometer tanto a formação da pastagem quanto o rebrote após o pastejo por competir por água, luz, nutrientes e espaço físico (Jakelaitis et al., 2010; Krenchinski et al., 2015).

Durante a formação de pastagem de Brachiaria brizantha, até $40 \%$ de perda da massa de forragem foi verificada quando em convivência com as plantas daninhas (Jakelaitis et al., 2010). No Sul do Estado do Paraná, o estabelecimento de trevo branco para pastejo sem intervenção no crescimento das plantas daninhas ocasionou perdas de $96 \%$ da massa seca do pasto (Schuster et al., 2013). Desta forma, é imprescindível que métodos eficientes de controle de plantas daninhas sejam desenvolvidos.

Uma combinação de métodos de controle é normalmente empregada no manejo de plantas daninhas em pastagens, em especial métodos mecânicos e químicos em conjunto (Madire et al., 2011). A presença das infestantes em pastagens pode ocorrer de maneira desuniforme e esporádica, muitas vezes inviabilizando pulverizações com herbicidas em área total (Shiratsuchi et al., 2003). Além disso, o fato de algumas plantas invasoras de pastagens apresentarem porte arbustivo ou arbóreo também dificulta operações com implementos de arrasto e autopropelidos, exigindo assim, práticas de aplicação localizadas de produtos fitossanitários. Usualmente, aplicações localizadas de herbicidas hormonais são empregadas posteriormente ao corte das plantas daninhas rente ao solo, pulverizando os produtos de maneira dirigida ao toco ou simplesmente na porção basal dos troncos das plantas (Ferrell et al., 2010).

Tecoma stans (L.) Juss. ex. Kunth (amarelinho) é uma planta exótica no Brasil que inicialmente foi cultivada para fins ornamentais e tornou-se uma importante planta daninha de porte arbustivo em pastagens (Biondi et al., 2008; Silva et al., 2008). Esta espécie prefere ambientes com luminosidade para o seu crescimento e pode apresentar mais de $70 \%$ de germinação de suas sementes, as quais são dispersas facilmente pela ação do vento. Também pode se propagar por pedaços de caule e raízes, característica inerente à rápida rebrota após o corte da parte aérea. Além disso, essa espécie também pode apresentar potencial alelopático (Lorenzi, 2000; Socolowski et al., 2011; Reis et al., 2014; Cipriani et al., 2014).

A aplicação de herbicidas hormonais na base das plantas ou sobre o caule logo após o corte foram opções interessantes no controle de outras espécies arbustivas, como Gleditsia triacanthos (Harmoney, 2016) e de Acacia farnesiana e Mimosa pteridofita (Carmona et al., 2001).

Atualmente as informações para $o$ controle de amarelinho em pastagens são escassas, bem como os estudos sobre o efeito de herbicidas em diferentes modalidades de aplicação sobre esta espécie. É possível que o controle de amarelinho seja eficaz, não apenas realizando o corte das plantas, mas também a posterior aplicação de herbicidas recomendados. O objetivo deste trabalho foi avaliar o desempenho e a seletividade de herbicidas hormonais aplicados em pósemergência dirigida ao toco logo após o corte da 
parte aérea visando ao controle de amarelinho (Tecoma stans) em pastagem de capim-tanzânia (Panicum maximum Jacq cv. Tanzânia).

\section{Material e Métodos}

O ensaio foi instalado na propriedade Fazenda São João, localizada no município de Bom Sucesso, no período de 31/01/2013 a 01/11/2013 $\left(23^{\circ} 44^{\prime} 28,28^{\prime \prime} \mathrm{S}, 51^{\circ} 43^{\prime} 6,48^{\prime \prime} \mathrm{O}\right.$, a 573 metros de altitude), em área de solo argiloso
$\left(\mathrm{pH}_{\mathrm{CaCl} 2}=5,3 ; 4,3 \%\right.$ M.O.; $69 \%$ argila; $7 \%$ areia).

A pastagem presente na área de instalação do experimento era o capim-tanzânia (Panicum maximum Jacq cv. Tanzânia), apresentando boa cobertura de solo e vigor vegetativo por ocasião da instalação do experimento. Os dados climáticos referentes ao período de condução do experimento encontram-se na Figura 1.

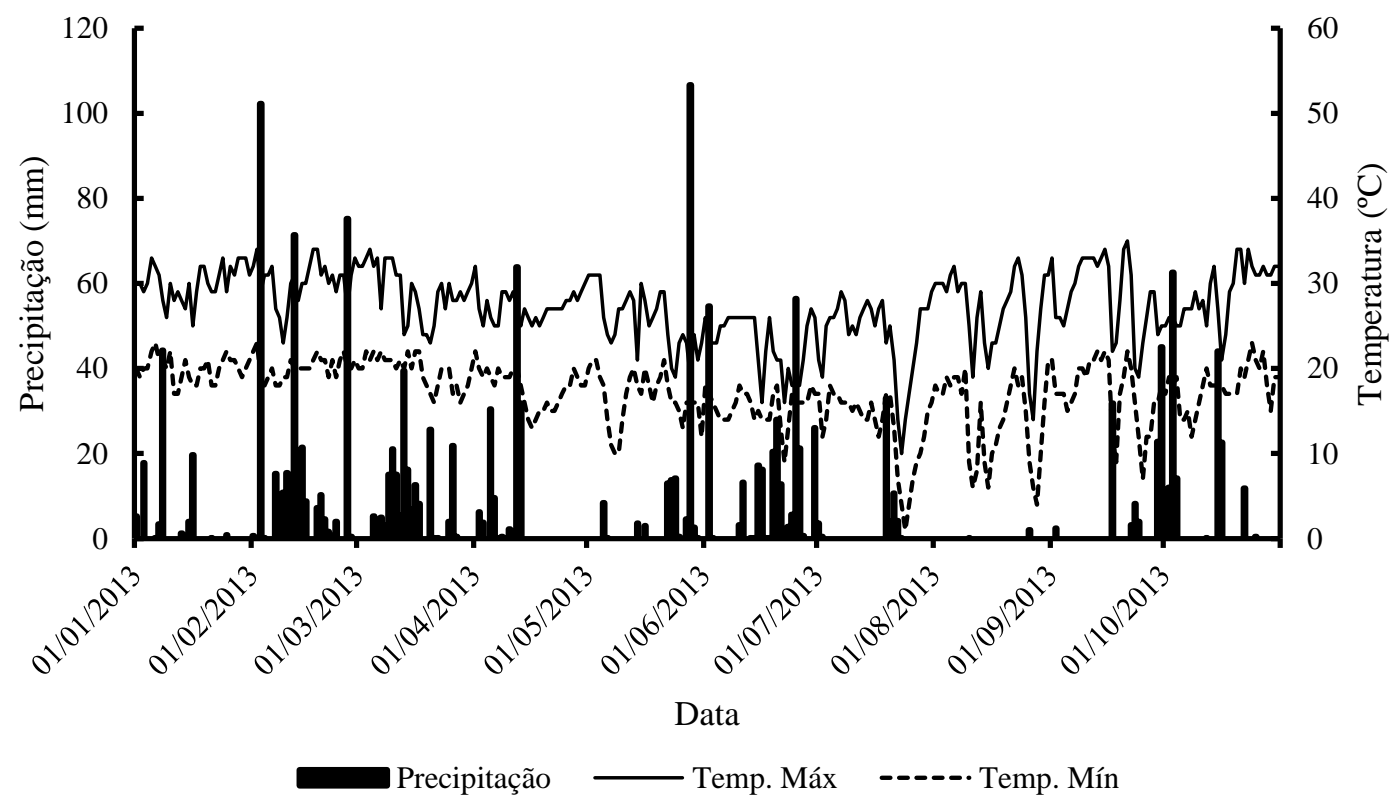

Figura 1. Dados de temperatura máxima e mínima e precipitação durante o período de condução do experimento. Fonte: INMET - Instituto Nacional de Meteorologia - Bom Sucesso (PR), 2013.

O delineamento utilizado foi $\mathrm{o}$ inteiramente casualizado, com sete tratamentos e dez repetições. Cada parcela correspondeu a uma planta adulta de amarelinho, sendo assim, cada tratamento foi composto por dez plantas. Os tratamentos (Tabela 1) foram constituídos pela aplicação de diferentes herbicidas hormonais, em jato dirigido ao toco das plantas imediatamente após o corte da parte aérea associado a uma rachadura em formato de cruz, além de uma testemunha sem herbicida, que serviu como padrão para as avaliações de controle e uma testemunha roçada, para avaliar a velocidade de rebrota em comparação com os produtos testados. As plantas de amarelinho apresentavam variabilidade na altura (30 centímetros a 3 metros de altura) e no diâmetro do caule ( 5 a 25 centímetros) por ocasião da realização das aplicações.

Para as aplicações dos tratamentos foi utilizado um pulverizador costal de pressão constante à base de $\mathrm{CO}_{2}$, equipado com uma ponta do tipo leque XR-110.02, sob pressão de $2 \mathrm{kgf} \mathrm{cm}^{-2}$. Os produtos comerciais foram diluídos nas caldas conforme descrito na Tabela 1 , na relação de $\mathrm{v} \mathrm{v}^{-1}(\%)$. As aplicações foram realizadas até que o volume de calda depositado nas plantas atingisse o ponto de escorrimento. 
Nos tratamentos em que foi prevista a aplicação na base (AB), estas foram realizadas no terço inferior das plantas, utilizando-se óleo diesel como diluente. No tratamento cinco, com aplicação dirigida no toco (AT), o caule foi cortado a uma altura de $5 \mathrm{~cm}$ em relação à superfície do solo e foi realizada a rachadura do toco em formato de cruz. Ambas as operações foram realizadas com um facão. Para esta modalidade de aplicação (AT), a calda foi preparada utilizando-se água como agente de diluição e a aplicação foi realizada imediatamente após o corte.

Tabela 1. Tratamentos, doses, concentração de produto comercial na calda e modalidade de aplicação utilizados no experimento para o controle de amarelinho. Bom Sucesso (PR), 2013.

\begin{tabular}{|c|c|c|}
\hline Tratamento & Concentração na calda (\%) & Modalidade de aplicação \\
\hline 1 - Testemunha sem aplicação & - & - \\
\hline $2-$ Testemunha roçada & - & - \\
\hline 3 - Triclopyr $\frac{1 /}{}\left(680\right.$ g i.a. $\left.\mathrm{L}^{-1}\right)$ & 4 & $\mathrm{AB}^{2} \stackrel{2}{ }$ \\
\hline 4 - Triclopyr (680 g i.a. $\left.\mathrm{L}^{-1}\right)$ & 3 & $\mathrm{AB}^{21}$ \\
\hline 5 - Picloram $1 /$ ( $\left(240\right.$ g e.a. L $\left.^{-1}\right)$ & 2 & $\mathrm{AT}^{2 /}$ \\
\hline $6-$ Picloram + triclopyr* & $1+1$ & $\mathrm{AB}^{2} \stackrel{2}{ }$ \\
\hline 7 - Picloram + triclopyr* & $2+2$ & $\mathrm{AB}^{21}$ \\
\hline
\end{tabular}

A aplicação dos herbicidas foi realizada em 31/01/2013 (8:00 - 9:00). No momento da aplicação o solo encontrava-se úmido, a temperatura do ar era de $22^{\circ} \mathrm{C}$, a umidade relativa do ar estava em $70 \%$, céu sem a presença de nuvens e ventos de $1,1 \mathrm{~km} \mathrm{~h}^{-1}$. No dia em que foi realizada a aplicação, a pastagem de capim-tanzânia apresentava altura média de 40 centímetros.

Para as avaliações de controle, utilizouse como referência as plantas existentes nas testemunhas sem herbicida e roçada. As variáveis avaliadas foram porcentagem de controle (escala visual, $0-100 \%$, onde $0 \%$ significa ausência de sintomas e $100 \%$ morte total das plantas de amarelinho) (EWRC, 1964) e a fitointoxicação da pastagem de capimtanzânia, adotando-se a mesma escala descrita para as avaliações de controle. Para as avaliações de fitointoxicação, as observações se limitaram à área adjacente à planta de amarelinho que havia recebido a aplicação dos herbicidas, o que correspondia a um raio de 20 a $30 \mathrm{~cm}$ de cada planta. Também foi avaliada a altura do rebrote de cada parcela escolhendo um rebrote por planta aleatoriamente. As avaliações ocorreram aos 30, 60, 180 e 270 dias após a aplicação (DAA).

Os dados foram submetidos à análise de variância pelo teste $\mathrm{F}$ e as médias comparadas pelo teste de Tukey, a 5\% de probabilidade. O software utilizado para as devidas análises estatísticas foi o SISVAR (Ferreira, 2008).

\section{Resultados e Discussão}

$\mathrm{Na}$ Tabela 2 e na Figura 2 estão apresentados, respectivamente, os níveis de controle de amarelinho e o tamanho do rebrote das plantas em função da aplicação dos diferentes herbicidas utilizados. A avaliação do tamanho do rebrote é importante, uma vez que esta espécie apresenta regeneração rápida e vigorosa após o corte do tronco ou após a utilização de herbicidas aplicados na parte aérea (Passini e Kranz, 1997). Na primeira avaliação de controle realizada aos 30 DAA, não foram observadas diferenças entre os tratamentos com aplicação de herbicidas (AB e AT) e a testemunha roçada, observando-se níveis de controle superiores a $90 \%$ para todos estes tratamentos (Tabela 2). 
Tabela 2. Níveis de controle de amarelinho aos 30, 60, 120, 180 e 270 dias após a aplicação (DAA) dos tratamentos. Bom Sucesso (PR), 2013.

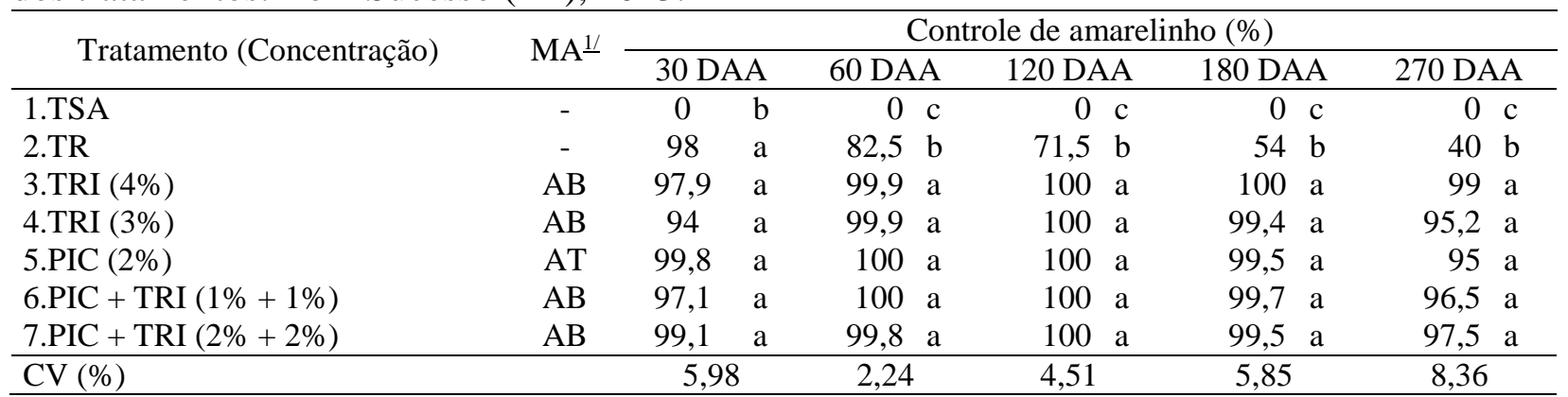

MA: modalidade de aplicação; TSA: testemunha sem aplicação; TR: testemunha roçada; TRI: triclopyr; PIC: picloram. ${ }^{\prime \prime} \mathrm{AB}$ : aplicação na base do caule com calda a base de óleo diesel; AT: aplicação no toco após corte em formato de cruz. Médias com letras iguais na coluna não diferem entre si a 5\% de probabilidade pelo teste de Tukey.

Observando apenas os resultados da primeira avaliação de controle (30 DAA), tanto a utilização de tratamentos herbicidas quanto a prática de roçagem das plantas de amarelinho resultaram em níveis de controle semelhantes (Tabela 2). Apesar disto, quando se verifica os dados de rebrota da primeira avaliação, observase que as plantas roçadas já possuíam, em média, rebrote de $9,3 \mathrm{~cm}$, enquanto que nos tratamentos onde foram empregados herbicidas não foi verificado a presença de plantas rebrotadas (Figura 2). Contudo, verificou-se que os caules das plantas ainda permaneciam verdes e apresentando resistência ao quebramento, o que descaracteriza $100 \%$ de controle.

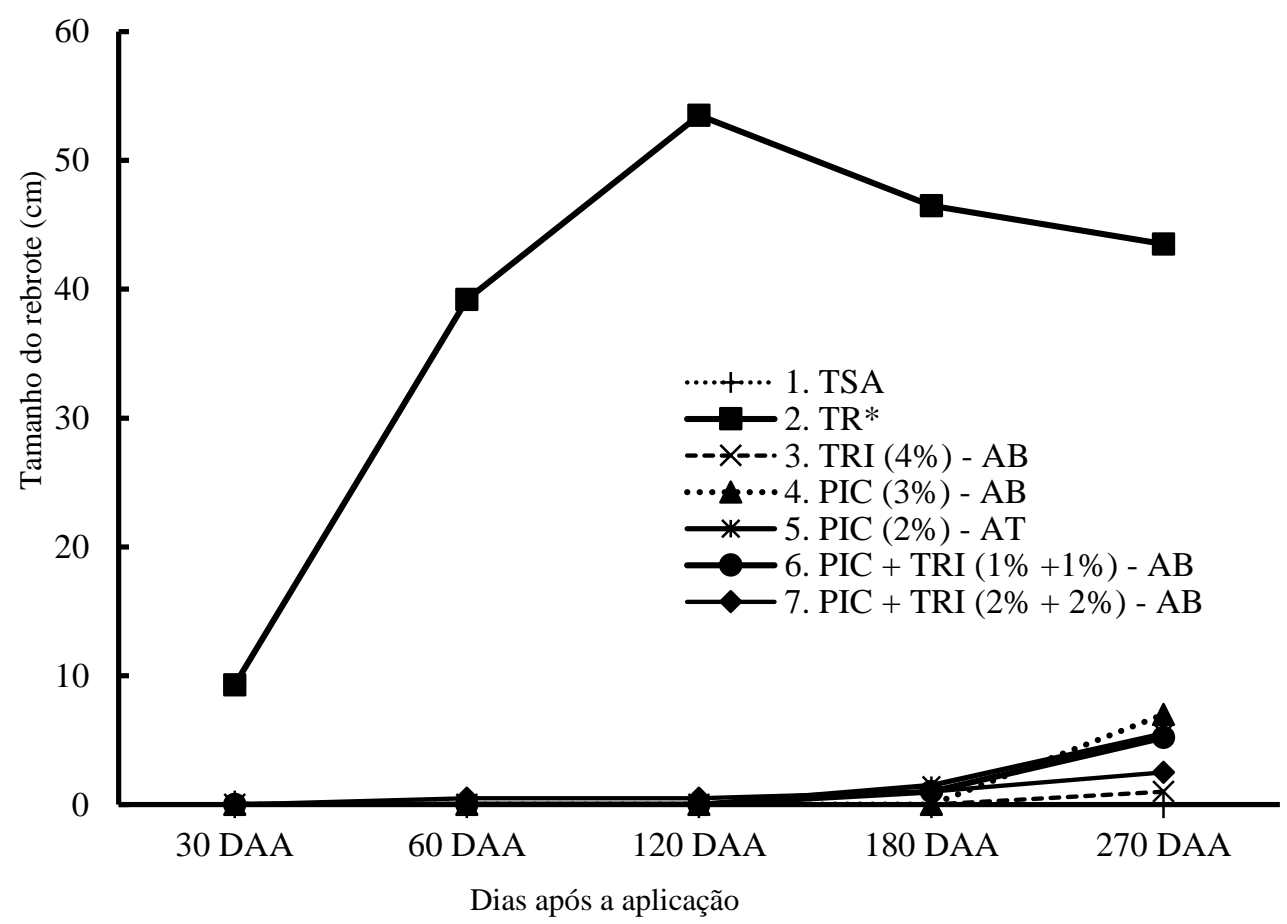

AB: aplicação na base; AT: aplicação no toco; TSA: testemunha sem aplicação; TR: testemunha roçada; TRI: triclopyr; PIC: picloram. *Difere e supera os demais tratamentos aos 30,60,120,180 e 270 DAA, a nível de 5\% de probabilidade, pelo teste de Tukey.

Figura 2. Altura do rebrote das plantas de amarelinho em diferentes períodos após a aplicação dos tratamentos. Bom Sucesso (PR), 2013. 
Aos 60 DAA, as plantas de amarelinho que receberam aplicação dos herbicidas, tanto $\mathrm{AB}$ quanto AT, permaneciam sofrendo efeito dos produtos, verificando-se níveis de controle próximos a $100 \%$ nestes tratamentos (Tabela 2). Em contrapartida, no tratamento onde se realizou a roçada da parte aérea das plantas, verificou-se redução nos níveis de controle, apesar destes ainda serem razoáveis. Esta redução no controle ocorreu pela rebrota das plantas, que, nesta avaliação, apresentavam tamanho médio de 39,2 cm (Figura 2).

$\mathrm{Na}$ avaliação posterior (120 DAA) os níveis de controle das plantas de amarelinho e o tamanho da rebrota não sofreram grandes variações, permanecendo semelhantes aos da avaliação realizada aos 60 DAA (Tabela 2). Neste período, a queda das temperaturas e a menor disponibilidade hídrica durante o inverno diminuem a agressividade de crescimento vegetativo, o que também foi constatado por Kanieski et al. (2012), que verificaram relação entre a diminuição da temperatura e das precipitações e o menor crescimento de algumas espécies arbóreas. Passini e Kranz (1997) constataram que $100 \%$ das plantas tratadas com a mistura comercial 2,4-D + picloram (4\%) apresentavam rebrote aos 152 DAA. No presente trabalho, aos 180 DAA, apenas o tratamento com triclopyr (4\%) com $\mathrm{AB}$ não apresentavam nenhum rebrote (Figura 2), entretanto, os outros tratamentos com herbicidas ainda foram eficientes para proporcionar excelentes resultados de controle (Tabela 2).

Caldeira e Castro (2012) testaram aplicações de picloram com e sem rachaduras mecânicas direcionadas ao toco de plantas de $T$. grandis e observaram resultados satisfatórios de controle, mesmo nos tratamentos em que não havia sido realizado nenhum dano físico no toco das plantas. DiTomaso e Kyser (2007) verificaram que a aplicação localizada de triclopyr no toco ou na base em plantas de Ailanthus altissima também resultou em controle acima de 90\%. Para o herbicida aminocyclopyrachlor, apenas $1 \%$ do produto aplicado nas folhas translocou até as raízes das plantas de amarelinho (Reis et al., 2015). Essa informação realça a importância da aplicação localizada no caule, como por exemplo AT ou $\mathrm{AB}$, que podem resultar em maiores translocações em relação a pulverizações foliares, por serem aplicados diretamente nos vasos das plantas.

Além do efeito de destruição de membranas e paredes celulares das plantas, o óleo diesel pode agir sistemicamente quando aplicados no toco (Akobundu, 1987; Carmona et al., 2001). A aplicação no toco apenas com óleo diesel é uma prática comum para o controle de plantas daninhas em pastagens. Em plantas de Acasia farmesiana e Mimosa pteridofita pouco desenvolvidas, apenas o pincelamento de óleo diesel no toco foi suficiente para o controle, entretanto ocorreu efeito antagônico quando misturado com 2,4-D + picloram (Carmona et al., 2001). No presente estudo não foi observado controle insatisfatório de picloram + triclopyr com AB diluído em calda com óleo diesel, o que sugere que não ocorreu antagonismo desta mistura. É possível que o óleo diesel tenha influenciado nos elevados níveis de controle de amarelinho nos tratamentos os quais o mesmo estava presente na calda.

Os dados de fitointoxicação do pasto de capim-tanzânia ao redor das plantas de amarelinho estão apresentados na Tabela 3. Na primeira avaliação, realizada aos 30 DAA, verificou-se que em todos os tratamentos com aplicação de herbicidas houve intoxicação severa das plantas de capim-tanzânia, as quais apresentavam elevadas injúrias provocadas pelos herbicidas aplicados nesta modalidade.

Em nova avaliação de fitointoxicação (60 DAA), verifica-se que no tratamento com aplicação no toco de picloram a 2\% (T5) houve acentuada recuperação das plantas de capimtanzânia dos sintomas provocados pelo herbicida. Nos demais tratamentos, as notas de fitointoxicação permaneceram semelhantes às da primeira avaliação, demonstrando a baixa seletividade destes herbicidas para as plantas de capim-tanzânia posicionadas imediatamente ao redor das plantas de amarelinho pulverizadas. 
Tabela 3. Porcentagem de fitointoxicação da pastagem de capim-tanzânia em um raio de 20 a 30 cm das plantas de amarelinho, aos 30, 60 e 120 dias após a aplicação dos tratamentos. Bom Sucesso (PR), 2013.

\begin{tabular}{|c|c|c|c|c|}
\hline \multirow{2}{*}{ Tratamento (Concentração) } & \multirow{2}{*}{$\mathrm{MA}^{1 /}$} & \multicolumn{3}{|c|}{ Fitointoxicação da pastagem (\%) } \\
\hline & & 30 DAA & 60 DAA & $120 \mathrm{DAA}$ \\
\hline 1.TSA & - & $0 \mathrm{~b}$ & 0 & $0 \mathrm{c}$ \\
\hline 2.TR & - & $0 \mathrm{~b}$ & 0 & $0 \mathrm{c}$ \\
\hline 3.TRI $(4,0 \%)$ & $\mathrm{AB}$ & 97,4 a & 100 & 78,5 a \\
\hline 4.TRI $(3,0 \%)$ & $\mathrm{AB}$ & 97,8 a & 100 & $67,5 \mathrm{ab}$ \\
\hline 5.PIC $(2,0 \%)$ & AT & $96 \mathrm{a}$ & 56,5 & $70 \mathrm{ab}$ \\
\hline 6.PIC + TRI $(1,0 \%+1,0 \%)$ & $\mathrm{AB}$ & $96,7 \mathrm{a}$ & 85,9 & $67 \mathrm{ab}$ \\
\hline 7.PIC + TRI $(2,0 \%+2,0 \%)$ & $\mathrm{AB}$ & 97,7 a & 96,1 & $62 \mathrm{~b}$ \\
\hline $\mathrm{CV}(\%)$ & & 3,19 & 21,45 & 23,06 \\
\hline
\end{tabular}

MA: modalidade de aplicação; TSA: testemunha sem aplicação; TR: testemunha roçada; TRI: triclopyr; PIC: picloram. ${ }^{1}$ AB: aplicação na base do caule com calda a base de óleo diesel; AT: aplicação no toco após corte em formato de cruz. Médias com letras iguais na coluna não diferem entre si a 5\% de probabilidade pelo teste de Tukey.

Aos 120 DAA a fitointoxicação pelos herbicidas apresentaram valores médios entre 62 e 78,5\% (Tabela 3), demonstrando uma tendência de redução na fitointoxicação da pastagem. As avaliações subsequentes (180 e 270 DAA) foram impossibilitadas pelo fato de uma geada ocorrida no dia 24/07/2013 ter comprometido a pastagem de capim-tanzânia (Figura 1). As plantas de amarelinho, porém, não sofreram com o fenômeno climático e, por isso, as avaliações de controle após esta data foram viáveis.

Apenas o corte da parte aérea das plantas daninhas não foi suficiente para controlá-las, devido à grande capacidade de rebrote (Figura 2). Com o controle utilizando a AT logo após o corte, as raízes ainda continuam consumindo carboidratos presentes no floema, fazendo com que a concentração de soluto seja menor nos meristemas radiculares em relação as áreas próximas ao corte. Desta forma, o movimento de seiva pelo vaso floemático continua descendente devido a diferença de potencial osmótico, carreando o herbicida aplicado no toco. O herbicida aplicado logo após o corte causa efeito inibitório das brotações e isto explica o motivo da velocidade de rebrote nas plantas ser maior quando não se procede a aplicação, realizando-se apenas a remoção física da parte aérea.

Os resultados de controle de amarelinho proporcionados pelos tratamentos empregados indicam que todos os herbicidas consistem em boas alternativas para o seu manejo. Em função do custo da mão-de-obra no controle de plantas daninhas em pastagem ser elevado, já que o manejo destas espécies arbustivas precisa ser realizado de maneira localizada, a utilização dos tratamentos com aplicação de triclopyr - AB (3\%) apresenta-se como opção interessante para o manejo de amarelinho. Comparado com os demais tratamentos, este dispensaria a necessidade de se realizar misturas entre herbicidas (aumento do custo de aplicação), bem como de se realizar o corte das plantas (maior emprego de mão-de-obra). Tratamentos com AB podem ser limitados quando aplicados em plantas mais velhas, por possuírem maiores massas de raízes e consequentemente, maiores quantidades de reservas para o rebrote. Por isso é essencial realizar esse tipo de aplicação (AB) em plantas mais jovens, com caules de até $45 \mathrm{~cm}$ de diâmetro e utilizando óleo como calda (Carmona et al., 2001; Ferrell et al., 2010), conforme executado nesse experimento.

Embora os herbicidas tenham apresentado considerável fitointoxicação na pastagem num raio de 20 a $30 \mathrm{~cm}$ de cada planta de amarelinho que recebeu a aplicação dos produtos, não houve sintomas nas demais áreas de pastagem. Portanto, embora tais tratamentos não possam ser considerados seletivos para aplicações em pós-emergência em área total, possivelmente em função das altas doses 
utilizadas, é possível utilizá-los em aplicações dirigidas às plantas de amarelinho.

Esses produtos apresentam residual no solo, o que pode comprometer culturas que possam vir a ser instaladas em áreas de pastagem (Santos et al., 2006; Carmo et al., 2008; Procópio et al., 2009). Isso torna mais maleável a utilização destes herbicidas de maneira localizada ao invés de em área total, fato que também valoriza métodos de aplicações dirigidas diretamente às plantas.

Esses métodos de controle valem para níveis de infestação baixos o suficiente para possibilitarem este tipo de aplicação, portanto sem prejudicar grandes áreas de pastagem. Caso a infestação seja alta, com risco de haver fitointoxicação em maiores áreas, é interessante adequar a metodologia de aplicação para que se diminua a deriva ao redor das plantas de amarelinho. Por exemplo, é possível utilizar pontas de pulverização que produzam gotas maiores e com leque ou cone de abertura reduzidos, de modo que a pulverização atinja apenas o toco ou utilizar um aparato que funcione como barreira física entre o alvo e a pastagem.

Até $6,77 \%$ e $11 \%$ de fitointoxicação de pastagem de grama-bermuda (C. lemfuensis) foi observada após a utilização, em área total, de produtos contendo triclopyr e picloram, respectivamente (Krenchinchi et al., 2015). Com herbicidas triclopyr e a mistura de 2,4-D + picloram, não foram verificadas intoxicação do gramado ( $P$. notatum) submetido ao controle de plantas daninhas em área total (Freitas et al., 2003). Em ambos os casos, os níveis de intoxicação das gramíneas foram menores do que os encontrados neste experimento. Porém, mesmo observando injúrias na pastagem localizada ao redor das plantas pulverizadas, é possível que o controle acima de 95\% (270 DAA) obtido com todos os tratamentos com herbicidas seja um benefício de suficiente interesse para tolerar-se o comprometimento de uma pequena área da pastagem ao redor das plantas pulverizadas.

\section{Conclusões}

Os tratamentos com os herbicidas avaliados foram considerados pouco seletivos para a pastagem de capim-tanzânia localizada num raio máximo de 20 a $30 \mathrm{~cm}$ das plantas de amarelinho pulverizadas, após aplicações em jato dirigido ao toco ou à base das plantas daninhas. No entanto, efeitos dos herbicidas foram apenas ao redor das plantas tratadas e não prejudicaram toda a área ocupada pela forrageira, podendo ser utilizados para manejo de amarelinho (Tecoma stans) em pastagem nestas modalidades de aplicação.

Todos os tratamentos com herbicidas, em ambas as modalidades de aplicação, na base do caule ou no toco logo após o corte, proporcionaram controle acima de $95 \%$ das plantas de amarelinho.

\section{Referências}

Akobundu, I.E. Weed science in the tropics: principles and practices. Norwich: J. Wiley, 1987. $522 \mathrm{p}$.

Biondi, D.; Bredow, E.A.; Leal, L. Influência do diâmetro de estacas no enraizamento de Tecoma stans (L.) Juss. ex Kunth. Ciências Agrárias, v.29, n.2, p.277-282, 2008.

Caldeira, S.F.; Castro, C.K.C. Herbicidas e danos físicos em tocos de teca para controle de brotos após o desbaste. Ciência Rural, v.42, n.10, p.1826-1832, 2012.

Carmo, M.L.; Procópio, S.O.; Pires, F.R.; Cargnelutti Filho, A.; Braz, G.B.P.; Silva, W.F.P.; Barroso, A.L.L. et al. Influência do período de cultivo de Panicum maximum (cultivar tanzânia) na fitorremediação de solo contaminado com picloram. Planta Daninha, v.26, n.2, p.315-322, 2008.

Carmona, R.; Araújo Neto, B.S.C.; Pereira, R.C. Controle de Acacia farnesiana e de Mimosa pteridofita em pastagem. Pesquisa Agropecuária Brasileira, v.36, n.10, p.13011307, 2001. 
Cipriani, F.A.; Kaplan, M.A.C.; Isaias, R.M.S.; Soares, G.L.G. Avaliação da fitotoxidez de Tecoma stans (L.) Kunth. Floresta e Ambiente, v.21, n.1, p.1-7, 2014.

DiTomaso, J.M.; Kyser, G.B. Control of Ailanthus altissima using stem herbicide application techniques. Arboriculture \& Urban Forestry, v.33, n.1, p.55-63, 2007.

EWRC (European Weed Research Council). Report of $3^{\text {rd }}$ and $4^{\text {th }}$ meetings of EWRC Committee of Methods in Weed Research. Weed Research, v.4, p.88, 1964.

Ferreira, D.F. SISVAR: um programa para análises e ensino de estatística. Revista Symposium, v.6, p.36-41, 2008.

Ferrell, J.; Enloe, S.; Sellers, B. Herbicide application techniques for woody plant control. Gainesville, FL: Agronomy Department, IFAS Extension, University of Florida, 2010. 4p. (Documento SS-AGR-260). Disponível em: http://edis.ifas.ufl.edu/pdffiles/AG/AG24500.p df. Acesso em: 15 jun. 2016.

Freitas, F.C.L.; Ferreira, L.R.; Silva, A.A.; Barbosa, J.G.; Miranda, G.V.; Machado, A.F.L. Eficiência do triclopyr no controle de plantas daninhas em gramado (Paspalum notatum). Planta Daninha, v.21, n.1, p.159-164, 2003.

Harmoney, K.R. Controlling honey locust (Gleditsia triacanthos) with cut stump and basal bark applied herbicides for grazed pasture. Weed Technology v.30, n.3, p.801-806, 2016.

Jakelaitis, A.; Oliveira Gil, J.; Simões, L.P.; Souza, K.V.; Ludtke, J. Efeitos da interferência de plantas daninhas na implantação de pastagem de Brachiaria brizantha. Revista Caatinga, v.23, n.1, p.8-14, 2010.

Kanieski, M.R.; Santos, T.L.; Graf Neto, J.; Souza, T.; Galvão, F.; Roderjan, C.V. Influência da precipitação e da temperatura no incremento diamétrico de espécies floreastais aluviais em Araucária-PR. Floresta e Ambiente, v.19, n.1, p.17-25, 2012.
Krenchinski, F.H.; Albrecht, A.J.P.; Albrecht, L.P.; Cesco, V.J.S.; Rodrigues, D.M.; Filho, R.V. Application rates and herbicide in weed control in pasture. Revista Brasileira de Herbicidas, v.14, n.4, p.271-279, 2015.

Lorenzi, H. Plantas ornamentais do Brasil: arbustivas, herbáceas e trepadeiras. $2^{\mathrm{a}}$ ed. Nova Odessa: Instituto Plantarum, 2000. 1088p.

Madire, L.G.; Wood, A.R.; Williams, H.E.; Neser, S. Potential agents for the biological control of Tecoma stans (L.) Juss ex Kunth var. stans (Bignoniaceae) in South Africa. African Entomology, v.19, n.2, p.434-442, 2011.

OECD/Food and Agriculture Organization of the United Nations. Agricultural Outlook 2015-2024. Paris: OECD, 2015. 148p.

Passini, T.; Kranz, W.M. Eficácia de herbicidas no controle de amarelinho (Tecoma stans) em pastagem. Planta Daninha, v.15, n.2, p.190197, 1997.

Procópio, S.O.; Carmo, M.L.; Pires, F.R.; Filho, A.C.; Braz, G.B.P.; Silva, W.F.P; Barroso, A.L.L. et al. Efeito da densidade populacional de Panicum maximum (cultivar Tanzânia) na fitorremediação de solo contaminado com o herbicida picloram. Ciências Agrárias, v.30, n.2, p.295-304, 2009.

Reis, F.C.; Medina Sotomayor, J.F.; Garcia, D.B.; Barroso, A.A.M.; Albrecht, A.J.P.; Filho, R.V. Germination and emergence of trumpet flower (Tecoma stans) under different environmental conditions. Planta Daninha, v.32, n.2, p.283-290, 2014.

Reis, F.C.; Tornisielo, V.L.; Cason, J.B.; Dias, A.C.R.; Freitas, M.; Sotomayor, J.F. et al. Ubtake, translocation and control of Trumpet Flower with aminocyclopyrachlor. Journal of Environmental Science and Health, Part B, v.50, n. 10, p.727-733, 2015.

Santos, M.V.; Freitas, F.C.L.; Ferreira, F.A.; Viana, R.G.; Tuffi Santos, L.D.; Fonseca, D.M. Eficácia e persistência no solo de herbicidas 
utilizados em pastagem. Planta Daninha, v.24, n.2, p.391-398, 2006.

Schuster, M.Z.; Szymczak, L.S.; Lustosa, S.B.C.; Pelissari, A.; Moraes, A.D.; Francisco, R. Interferência de plantas daninhas no estabelecimento do trevo branco como cultura forrageira. Ciência Rural, v.43, n.12, p.21482153, 2013.

Shiratsuchi, L.S.; Christoffoleti, P.J.; Fontes, J.R.A. Aplicação localizada de herbicidas. Plantaltina: Documentos 91/Embrapa Cerrados, 2003, 18p.

Silva, J.A.; Reis, T.E.S.; Reis, L.C. Análise da infestação do amarelinho (Tecoma stans) na zona rural do município de Bandeirantes - PR. Ciências Agrárias, v.29, n.1, p.83-92, 2008.

Socolowski, F.; Vieira, D.C.M.; Takaki, M. Massa das sementes de Tecoma stans L. Juss. ex Kunth (Bignoniaceae): efeitos na emergência e desenvolvimento de suas plântulas no sol e na sombra. Biota Neotropical, v.11, n.2, p.171178, 2011.

Souza Filho, A.P.S. Interferência potencialmente alelopática do capim-gengibre (Paspalum maritimum) em áreas de pastagens cultivadas. Planta Daninha, v.24, n.3, p.451456, 2006. 